Session 2525

\title{
Effectively Using Quantitative Indices of Conative Ability to Guide Teams
}

\author{
Reid Bailey \\ Department of Aerospace and Mechanical Engineering \\ University of Arizona \\ rrbailey@u.arizona.edu
}

\begin{abstract}
The success of an engineering design project is reliant upon individuals working effectively in teams. Due to this importance, quantitative indices of interpersonal behaviors are frequently used to form teams with a diverse set of qualities. In this paper, the focus is not on forming teams with indices but instead on the effects of informing individuals of their interpersonal behavioral tendencies as characterized by a quantitative metric, the Kolbe A Index. The Kolbe A Index is used to assess each student's instinctive tendency to use certain approaches in handling a problem (i.e., their conative ability). It is hypothesized that merely knowing ones instinctive tendencies as measured by the Kolbe Index will improve team performance, regardless of team composition. The results indicate that something more than merely knowing ones Kolbe Index, such as stronger coaching and support for use of the index, is needed to improve team performance.

The students involved in this study are all in a first-year engineering class at the University of Arizona that involves three projects over the course of one term. Quantitative results are gained from performance indices for each of the three projects. In addition, student surveys are used to gain further insight concerning the hypothesis. Throughout this paper, the emphasis is on building effective teams in general more than specifically building effective first-year engineering student design teams.
\end{abstract}

\section{MOTIVATION}

The success of an engineering design project is largely dependent upon individuals working effectively together as a team. In addition to technical skills required for a project, a critical part of forming successful teams is matching interpersonal styles of the individual team members. Because information on interpersonal styles is often difficult to obtain, different indicators have been developed and used to form teams. Prominent examples of such indicators are the MyersBriggs Type Indicator ${ }^{1}$, the Keirsey Temperament Sorter ${ }^{2}$, and the Kolbe Index. In this paper, the focus is on using the Kolbe Index, which measures an individuals instincts and drive.

The Kolbe Index has been used to successfully form teams with the fundamental idea being that a successful team is 1) composed of people with diverse Kolbe Indices and 2) balanced (so that one type of person cannot dominate team activities). There are many times, however, when team composition is based on other issues such as technical competence in the areas needed for a project and personnel availability. In such cases where the Kolbe Index is not the dominant

Proceedings of the 2002 American Society for Engineering Education Annual Conference \& Exposition Copyright (C) 2002, American Society for Engineering Education 
factor in team selection, can the Kolbe results be useful in improving team success?

Furthermore, if a manager forms a team using Kolbe Indices, should the team be informed of their scores? These questions are addressed in this paper through a preliminary study involving a first-year engineering design class at the University of Arizona.

The study presented in this paper examines whether mere knowledge of one's Kolbe Index positively affects team performance. It is hypothesized that such feedback of your instinctual approach to solving problems (as reflected by the Kolbe Index) will improve the performance of a team.

\section{FRAME OF REFERENCE}

Indicators relating how an individual interacts with the environment measure ones conative skills. The conative dimension concerns drive, motivation, and ones instinctual approach to solving problems. This is in contrast to the cognitive (concerning intelligence) and affective (concerning the temperament of an individual) dimensions. While cognitive abilities and technical skills of individuals on a team undoubtedly affect team performance, a growing view is that even the most skillful team cannot reach its potential without complementary conative personalities. Hence, if ones goal is to form and guide a successful team, the conative abilities of the team members must be known.

Previous research has been conducted on the validity of using different personality measures to gauge team performance ${ }^{3-4}$. Perhaps the most commonly used metric is the Myers-Briggs Type Indicator (MBTI), which measures the affective dimension ${ }^{5-7}$. The predominant result concerning MBTI is that the more similar a group of individuals are, the less well they will perform together as a team. A more detailed review of the use of the MBTI to form teams is in Reference 8.

The Kolbe Index is supported by significant research validating its ability to characterize an individual's conative abilities'. Furthermore, there is growing evidence that it is effective in constructing successful teams. A study involving MBA students at the University of Chicago's Business School concluded that the Kolbe Index was effective in predicting team performance ${ }^{9}$. Another study at the University of Arizona's Department of Systems and Industrial Engineering provides further evidence of a correlation between Kolbe indicators and team performance ${ }^{10}$.

Several additional characteristics of the Kolbe Index need to be introduced. First, the Kolbe Index has been proven to be consistent over time. One statistic which characterizes Kolbe's testretest stability is that the operating zones for each action mode (see the next section for description of "operating zone" and "action mode") for $90 \%$ of the test-takers did not change when retested 8 to 15 months after the original testing ${ }^{9}$. Such constancy supports the validity of the Kolbe Index and is important if using the index to form permanent teams. Another critical attribute of the Kolbe Index is its unbiased nature. Research has been performed on historical data to show that gender, race, socio-economic background, age, and ethnic origin are not correlated to the Kolbe Index. From this research, the Kolbe Index is shown to measure conative abilities independently of these other factors. 


\section{Kolbe Conative Index}

The Kolbe Index classifies an individual's instinctual approach to addressing a problem into four continua: 1) probing, 2) organizing, 3) improvising, and 4) constructing. Each of these four continua has a corresponding "Action Mode," which are 1) Fact Finder, 2) Follow Through, 3) Quick Start, and 4) Implementer, respectively. In very general terms, a Fact Finder needs to investigate topics in depth, a person with high Follow Through ratings seeks a sense of order, a Quick Starter is comfortable with the risks involved with initiating change, and an Implementer is most comfortable when ideas are converted into physical objects. In Table 1, comfortable tasks for each action mode are listed.

\section{Table 1 Actions for Different Action Modes}

\begin{tabular}{|c|c|c|c|}
\hline FACT FINDER & FOLLOW THROUGH & QUICK START & IMPLEMENTER \\
\hline probe & structure & invent & build \\
\hline define & coordinate & risk & fix \\
\hline calculate & arrange & challenge & practice \\
\hline specify & plan & originate & construct \\
\hline prove & budget & devise & demonstrate \\
\hline evaluate & integrate & reform & form \\
\hline formalize & consolidate & improvise & shape \\
\hline
\end{tabular}

The raw scores from the Kolbe Index "reflect the frequency with which the subject would tend to initiate, respond to, or resist proving, organizing, improvising, and constructing behaviors" 9 . The lists in Table 1 are tasks with which an initiator in each action mode would be comfortable.

The raw scores for each action mode range from 1 to 10, with high scores representing an initiate operating zone, low scores a prevent (or, resist) operating zone, and scores between 4 and 6 representing a response operating zone. Someone in the initiate operating zone for an action mode will demand that performing in the corresponding action mode is necessary (e.g., "We must find the facts before proceeding" - initiate operating zone for the Fact Finder action mode). While someone in a response operating zone will not be as insistent, they have the ability to work in that manner. An individual in a prevent operating zone is not comfortable with a particular action mode and will actively work to avoid such behavior (e.g., "We cannot start building our final design before we have a better plan" - prevent operating zone for the implementer action mode).

An important assumption embedded in the Kolbe Index is that all individuals have roughly the same amount of mental, or instinctual, energy to allocate to the four action modes. On the scales used in the Kolbe Index, the total energy is always between 18 and 22. Therefore, being a strong initiator in two action modes will require so much mental energy that one cannot be an initiator in a third action mode, too. Figure 1 shows a graphical interpretation of an individual's Kolbe Index. This individual initiates Fact Finding and Follow Through while preventing in the Quick Start and Implementer action modes. 


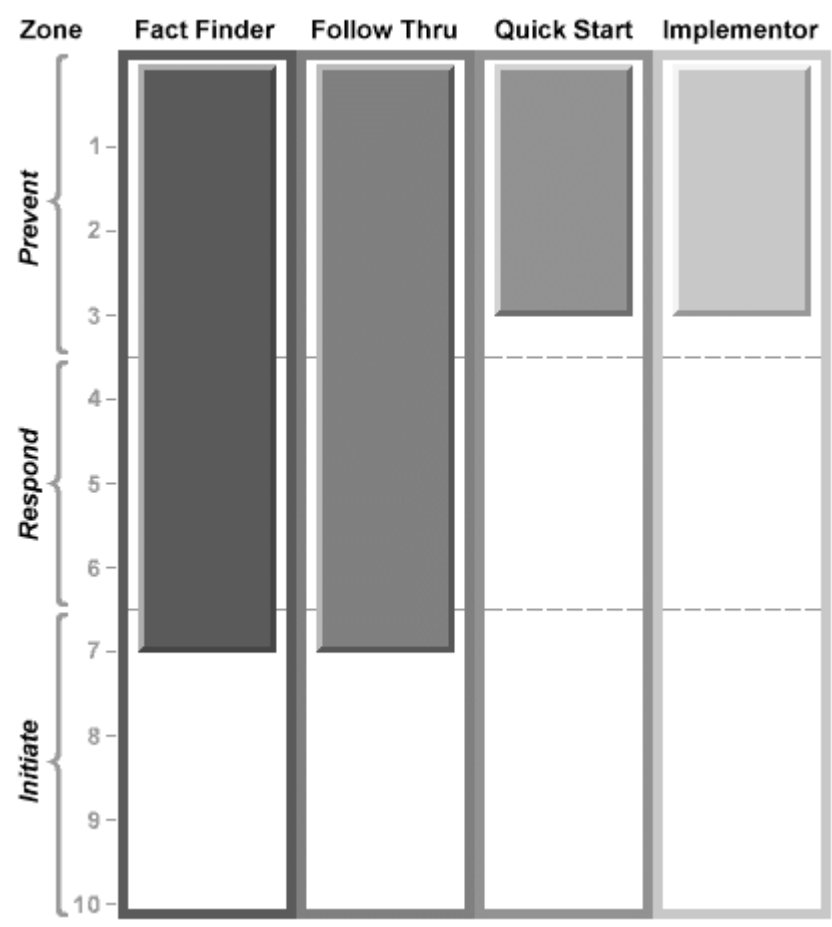

Figure 1 Sample Kolbe Index Score

While one can find dimensions of the Kolbe Index that appear similar to the MBTI, research has shown that no statistically significant relationship exists between the two measures ${ }^{9}$. The theoretical support for the distinctions between the two measures is as follows: the Kolbe Index indicates how someone will behave while the MBTI indicates how someone wants to behave. Stated another way, the Kolbe Index is a conative measure while the MBTI has stronger affective roots. This distinction is supported experimentally by the high test-retest reliability of the Kolbe Index as compared to the MBTI - how someone does behave changes less over time than ones preferences for how they would like to behave ${ }^{9}$. Because the actual behaviors of team members determine team success, the direct relationship of the Kolbe Index to how someone does act has clear implications for teaming.

\section{THE STUDY}

\section{Experimental Design}

To determine if knowledge of one's Kolbe Index affects team performance, a pretest-posttest control group design is used. The merits of such an experimental design are well documented, including its ability to handle threats to internal validity from maturation, history, instrumentation, and testing effects ${ }^{11}$.

One section of students in a first-year engineering design class at the University of Arizona is the focus of the study. The instructor grouped these students into teams randomly at the beginning of the semester. Over the course of the semester, each team completed three projects: the design of a catapult, of a tractor, and of a solar oven. For the first two projects, the students did not know their Kolbe Index. Before the third project, the students were given their Kolbe results and one day in class was used to describe the meaning of the results and how to use them. The 
control group consisted of three other sections of the same first year engineering design class that were taught by different instructors. The experimental design is shown graphically in Table 2 .

Table 2 Experimental Design

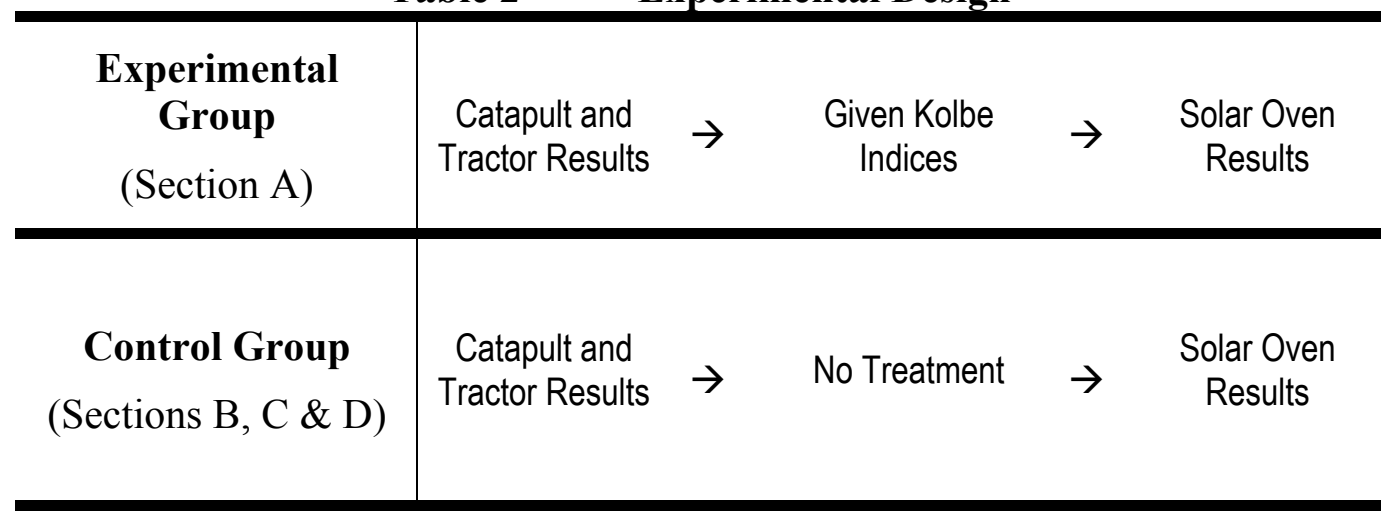

The three design projects are appropriate to study engineering design team performance for several reasons. First, each goes beyond analysis to truly involve design and synthesis. One way this is evidenced is through their openness: there is not a single right answer to any of them. Secondly, each project has a clear, quantitative objective that is shared among both the experimental and control groups. For example, the objective in the tractor project is to maximize the energy transferred from the tractor to the weight while minimizing the cost (which is modeled as $\$ 0.40$ per rubber band used). This objective is quantified into a performance index used by all four sections with the following equation:

$$
\text { performance index }=\frac{(\text { distance lifted })(\text { weight })}{(\$ 0.40)(\# \text { of rubber bands })}
$$

More information on all three of the projects is available at $h t t p: / / w w w . e n g r . a r i z o n a . e d u /$ engr102\%.

In addition to the scores on each project, a survey was given to the experimental group. The purpose of the survey is to get direct feedback from the students concerning the effect of the Kolbe Index of their team's performance.

\section{The Sample}

The four sections of the first year engineering design course involved in this study each had between forty and forty-five students. All four sections used the same textbooks and worked on the same projects. The author of this paper taught the experimental section while two other faculty taught the three control group sections. The differences in teaching style and content between the three faculty involved is one threat to the internal validity of this study. Because observations are taken both before and after the introduction of the Kolbe Index, however, this threat is minimized (i.e., any differences in teaching styles would affect the catapult and tractor results similarly to how they would affect the solar oven results).

One problem with the sample is that not all of the students in the experimental group could take the Kolbe Index. Four of the eight groups had at least half of their team members take the Kolbe Index test. Seven of the eight groups had at least two people take the Kolbe Index (the groups were composed of between four and six students. 
An entire class period was spent discussing the meaning of the Kolbe results with the experimental group (with over 85\% attendance for that class). A portion of this time was used to explain how to use the results to work effectively in teams. No additional coaching was provided to the students to maintain the validity of the study. There is evidence that merely giving more attention to a group (regardless of the nature of the attention) will improve its performance, therefore the level of attention before and after the Kolbe Index results were received by the students could not change significantly. This study focuses on the effects of knowing ones Kolbe Index, not on the effects of additional team coaching. None of the control group sections took the Kolbe Index or discussed it in class.

\section{RESULTS}

In Table 3, the average scores on each project for the control group are compared to the experimental group.

Table 3 Project Scores

\begin{tabular}{|cl|c|c||c|}
\cline { 3 - 5 } \multicolumn{1}{c|}{} & $\begin{array}{c}\text { I. Catapult } \\
\text { (meters) }\end{array}$ & $\begin{array}{c}\text { II. Tractor } \\
(\mathrm{Nm} / \$)\end{array}$ & $\begin{array}{c}\text { III. Solar Oven } \\
(\mathrm{deg} \mathrm{F} / \mathbf{})\end{array}$ \\
\hline $\begin{array}{c}\text { Experimental } \\
\text { Group }\end{array}$ & Average Score & 30.3 & 4.68 & 48.6 \\
\cline { 2 - 5 } & \% of Control Group Score & $\mathbf{8 8 . 3 \%}$ & $\mathbf{8 6 . 9 \%}$ & $\mathbf{7 4 . 7 \%}$ \\
\hline $\begin{array}{c}\text { Control } \\
\text { Group }\end{array}$ & Average Score & 34.3 & 5.38 & 65.1 \\
\cline { 2 - 5 } & \% of Control Group Score & $100 \%$ & $100 \%$ & $100 \%$ \\
\hline
\end{tabular}

The scores for the experimental group are shown to be lower than the control group for the first two projects (before the Kolbe Index was taken) by roughly $87.5 \%$. For the third project, the scores of the experimental group are even worse at roughly $75 \%$ of the control group scores. The hypothesis that the experimental group's scores should increase after taking the Kolbe Index is not supported. Ideas why the results are contrary to expectations are discussed in the following section.

The survey completed by the students at the end of the semester provides important information in determining why the hypothesis is not supported. In Table 4, results from the five survey questions are shown. The scale used ranges from 1 (strongly disagree with statement) to 5 (strongly agree with statement). 
Table $4 \quad$ Survey Results

\begin{tabular}{|c|l|c|}
\hline & Statement & Average Score \\
\hline 1 & I feel that the Kolbe results were accurate. & 4.25 \\
\hline 2 & The Kolbe results helped me better understand myself. & 3.3 \\
\hline 3 & $\begin{array}{l}\text { The Kolbe results helped me better understand how I can effectively } \\
\text { work on a team. }\end{array}$ & 3.3 \\
\hline 4 & $\begin{array}{l}\text { I changed how I worked on my ENGR 102 design team based on the } \\
\text { Kolbe results. }\end{array}$ & 2.7 \\
\hline 5 & $\begin{array}{l}\text { My work on the solar oven project improved (in comparison to the } \\
\text { first two projects) due to taking the Kolbe test. }\end{array}$ \\
\hline
\end{tabular}

While the students do feel quite confident in the accuracy of the Kolbe test, they are somewhat less confident that the Kolbe Index has helped them better understand how to work on a team. Furthermore, when asked if they changed how they worked on their teams as a result of the Kolbe Index, the students are clear that they changed little if anything. Correspondingly, the students did not feel that their work on the final project improved due to taking the Kolbe Index. In the next section, the meaning of the survey results and the project scores is discussed.

\section{DISCUSSION: LEARNING FROM THE RESULTS}

In this section, reasons are asserted to explain why gaining knowledge of ones instinctual approach to solving problems did not improve the performance of student teams in this study. Three explanations as to why the hypothesis is not supported are explored here:

* the students did not know enough about how to use the Kolbe Index results and/or did not see value in spending time applying the results to their team behavior;

* problems with the sample group and/or with the structure of the study obscured any support for the hypothesis; and,

* regardless of lack of student knowledge and motivation about how to use the Kolbe Index and any problems with the study, merely knowing ones Kolbe results is not enough to positively affect team performance.

While the students were educated during class about how to use the Kolbe Index results (and wrote essays about how to use the results), it is clear from the survey that few if any students changed their behaviors during the third project based on the Kolbe Index results. This is the case despite the students' confidence in the accuracy of the Kolbe Index as indicated by their response to the first survey question. It is very possibly the case that with more "coaching" and continual support, the students would have been able to apply the results more effectively to their team activities.

Another possibility is that the study was not designed or executed in a manner that could detect support for the hypothesis. The main threat to the validity of the results from this study is the fact that many of the students in the experimental group did not take the Kolbe test. Stronger incentives are needed in the future for students to take the test. Hence, the negative results in this 
study actually indicate that when several, but not all, members of a group take the Kolbe Index, the performance of the team as a whole is not improved. Having all of the group members take the Kolbe Index could certainly lead to different results. As for the structure of the study, the pretest-posttest control group design is a strength of this study and should not have biased the results.

It is the belief of the author that a second iteration of this study in which students are more thoroughly instructed on how to use the results and in which all of the students in the experimental group take the Kolbe Index is warranted before concluding that knowledge of ones Kolbe Index does not affect team performance. The results of such a study could have important implications concerning how to best use the Kolbe Index. For instance, if a manager forms a team based on individuals' Kolbe Indices, should that manager inform the team members of their scores or not? Or, if a team is formed based on other factors, is there merit in taking the Kolbe Index and informing the team members of their scores. Questions such as these could be answered from further research.

\section{CLOSURE AND FURTHER WORK}

Understanding the effects of informing team members of their Kolbe Indices is important knowledge for effectively constructing and managing a team using Kolbe results. From the results presented here, merely informing some team members of their results is not sufficient to improve team performance. It is asserted that additional instruction and reinforcement and that

providing Kolbe feedback to entire teams are plausible changes that could significantly affect the results. Further work will focus on evaluating the effects of such changes on team performance.

\section{ACKNOWLEDGEMENTS}

The author would like to thank the students in ENGR 102 at the University of Arizona in Fall 2001 and the instructors from the control group sections, Bruce Simon and Jack Lyon. The willingness of Kolbe Corp. to participate in this study is also greatly appreciated.

\section{REFERENCES}

1. Myers, I.B. and Myers, P.B. 1995. Gifts Differing: Understanding Personality Type. Consulting Psychologist Press.

2. Keirsey, D. 2000. http://www.keirsey.com, accessed on January 12, 2002.

3. Barrick, M.R. and Mount, M. K. 1991. The big five personality dimensions and job performance: a metaanalysis, Personnel Psychology, 32: 361-368.

4. Berry, E. and Lingard R. 2001. "Teaching communication and teamwork in engineering and computer science", American Society for Engineering Education Annual Conference, Sante Fe, New Mexico: Session 2330, http://www.ecs.csun.edu/ rlingard/Publications.

5. Wilde, D.J. 1997. "Using Team Preferences to Guide Design Team Composition,” ASME Design Theory and Methodology, DETC/DTM-3980, Sacramento, American Society of Mechanical Engineers.

6. Wilde, D.J., 1999. "Design Team Roles”, ASME Design Theory and Methodology, paper DTM-99 003, Las Vegas, American Society of Mechanical Engineers.

7. Jensen, D., Feland, J., Bowe, M., Self, B. 2000. "A 6-Hats Based Team Formation Strategy: Development and Comparison with an MBTI Based Approach", American Society for Engineering Education Annual Conference, St Louis.

Proceedings of the 2002 American Society for Engineering Education Annual Conference \& Exposition Copyright (C) 2002, American Society for Engineering Education 
8. Hammer, A.L. and Huszczo, G.E. 1996. Teams, in MBTI Applications, edited by Hammer, A.L. Palo Alto: Consulting Psychologists Press.

9. 2001. Kolbe Statistical Handbook. Kolbe Corp.

10. Fitzpatrick, E., Askin, R., Goldberg, J. 2001. Using student conative behaviors and technical skills to form effective project teams, ASEE/IEEE Frontiers in Education Conference, Reno, Nevada, Session S2G.

11. Singleton, R, Straits, B., Straits, M.M. 1993. Approaches to Social Research. Oxford University Press.

REID BAILEY is an Adjunct Assistant Professor in the Department of Aerospace and Mechanical Engineering at the University of Arizona. His research interests include engineering design, environmental issues affecting design, and engineering education. He received his B.S. from Duke University and both his M.S. and Ph.D. from the Georgia Institute of Technology. 